\title{
Erythropoiesis-stimulating agents and quality of life: personal journeys of a cancer survivor, oncologist, and two cancer health services researchers
}

\author{
C L Bennett ${ }^{\star}, 1,2,3,4$ and J Bian ${ }^{1}$ \\ ${ }^{1}$ Southern Network on Adverse Reactions (SONAR) Program, South Carolina College of Pharmacy, Columbia, SC, USA; ${ }^{2}$ Arnold \\ School of Public Health, University of South Carolina, Columbia, SC, USA; ${ }^{3}$ Hollings Cancer Center, Medical University of South \\ Carolina, Charleston, SC, USA and ${ }^{4}$ WJB Dorn VA Medical Center, Columbia, SC, USA
}

We write this editorial as a cancer survivor (CLB), an oncologist (CLB), and two cancer health services researchers (CLB, JB) in deference to many experts who have formally investigated psychometrics and quality of life (QOL) outcomes among cancer patients who receive erythropoiesis-stimulating agents (ESAs). In this editorial, we report the route by which we have evaluated and continue to consider trade-offs among ESA-treated cancer patients between increased mortality rates, thromboembolic events, transfusions due to chemotherapy-associated anaemia, and QOL. In this journey, we travel behind Brian Leyland-Jones, an oncologist and clinical trialist, who just reported his own personal journey investigating ESAs (Leyland-Jones, 2013).

As noted by Leyland-Jones, these journeys began at the end of the 1980s. The oncology world was excited and hopeful that ESAs would markedly improve survival rates of cancer patients undergoing chemotherapy and/or radiation therapy. He reported that the thought process was all too obvious. Basic science manuscripts and scientific presentations pictured partial oxygen pressure histograms showing that oxygenation levels differed between normal tissues and cancerous tissues. Pre-clinical studies of cancer cell lines reported that erythropoietin (EPO) enhanced cytotoxicity, enhanced anti-tumour immune responses, and improved radiosensitivity (Leyland-Jones, 2013). Basic science studies identified improved blood flow oxygenation to cancer cells, differential effects on haematopoietic and non-haematopoietic malignant cells, prominent anti-tumour effects when mice bearing human ovarian cancer cells were exposed to EPO and cisplatin, and anti-tumour effects on human medulloblastoma cell lines (Silver and Piver, 1999). In the clinical area, Glaser et al (2001) reported that EPO-induction of higher epoetin-levels improved the prognosis of persons with head and neck cancer who were undergoing preoperative chemoradiotherapy. A pivotal clinical trial by
Littlewood et al (2001) showed a 25\% improvement in 1-year survival and a 6-month overall survival benefit with epoetin $v s$ placebo among persons with head and neck cancer who received non-platinum chemotherapy.

However, beginning in 2001, this simple story became far more complex and even negative. Preclinical studies from basic scientists primarily in the United States identified erythropoietin receptors (EpoRs) on cancer cell lines, EPO-induced activation of important cancer pathways often mediated via EpoRs, and ultimately induce cell proliferation, resistance to chemotherapy and radiation therapy, and cancer cell growth (Bennett et al, 2010). Worrisome results of clinical studies followed. Concerning preclinical research studies continued to be reported-and these findings continue to be reported. To date, none of these worrisome preclinical research findings have been replicated by scientists employed by manufacturers of ESAs-instilling controversy into whether preclinical research studies are in fact replicable (Begley and Ellis, 2012).

Michael Henke and Brian Leyland-Jones opened the eyes of the clinical oncology world to concerns of increased mortality rates with ESA administration to patients with head and neck cancer undergoing radiation therapy or patients with metastatic breast cancer undergoing first-line chemotherapy, respectively (Henke et al, 2003; Leyland-Jones and BEST Investigators and Study Group, 2003). Leyland-Jones and Henke each expressed surprise when initial findings of their studies became apparent to them as clinical researchers. The optimism expressed by the acronyms of their studies, BEST and ENHANCE, had changed to pessimism. In 2008, this pessimism grew even more as Bennett et al reported 1.10 -fold increased risks of mortality among cancer patients who received ESAs vs placebo on control (in collaboration with a large network of clinicians and methodologists) (Bennett et al, 2008) Subsequently, as noted by Bohlius et al earlier in this Volume of 
the British Journal of Cancer, three subsequently published metaanalyses reported by researchers who were not funded by the pharmaceutical industry identified increased risks for either on study mortality or overall survival (Bohlius et al, 2014). In contrast, none of seven meta-analyses reported since 2008 by researchers with funding from ESA manufacturers have identified these mortality risks. This distinction between results from researchers with $v s$ without funding from ESA manufacturers in the setting of mortality mirrors the 2010 report of Bennett et al of differences in preclinical research findings on EpoRs by academic researchers $v s$ manufacturer-employed scientists (Bennett et al, 2010).

Another clinical concern soon appeared. In 2006, Bohlius et al reported a meta-analysis identifying a 1.57 -fold increased thromboembolic risks with ESA administration to cancer patients undergoing chemotherapy (Bohlis et al, 2006). These findings were replicated in numerous meta-analyses, including the one by Bennett et al in 2008.

The history of ESAs and their effects on QOL followed similar trajectories. In the early days of EPO administration to cancer patients, organisations like the ORTHO BIOTECH-sponsored fatigue coalition highlighted the debilitating effects of fatigue (Vogelzang et al, 1997). Oncologists and patients flocked to ESA administration. Outside of many large hospitals in the United States, a large bus was parked and clinicians could experience firsthand the effects of fatigue and the rapid 'quality of life benefits' of 'correction of anemia' (John, 2007). Observational databases reinforced the positive QOL benefits of ESAs and increased haemoglobin levels (Bohlius et al, 2014).

As with preclinical research studies on EpoRs and clinical trials evaluating survival and mortality, enthusiasm for QOL benefits hit roadblocks. Food and Drug Administration (FDA)-employed statisticians reported at the 2008 Oncology Drug Advisory Committee that QOL measures used in clinical trials were not valid when reviewed according to proposed guidelines from the FDA. ESA manufacturers were required to remove from FDAapproved product labels all statements related to potential QOL benefits with ESAs in the cancer setting. The controversy of QOL and ESAs continues alongside those outlined for preclinical findings and mortality findings. The American Society of Clinical Oncology, the American Society of Hematology, and the FDA explicitly do not support the use of ESAs to improve QOL as they consider the data supporting this recommendation as inconclusive. In contrast, as noted by Bohlius et al, the European Organization for the Research and Treatment of Cancer and the European Society of Medical Oncology do support ESA administration to improve QOL in cancer patients (Bohlius et al, 2014).

Bohlius et al report earlier in this Volume of the British Journal of Cancer that QOL controversies related to ESA administration in the cancer setting continue. Prior meta-analyses identified reductions in fatigue-related symptoms in cancer patients, whereas others had not. These meta-analyses had limitations such as being restricted to published literature and may be affected by biases resulting from either publication or outcome reporting. The currently reported meta-analysis of 37 randomised controlled trials with 10581 patients includes 21 randomised controlled trials that were placebo controlled. QOL was the primary endpoint in 11 studies and a secondary end-point in 25 studies. Most studies administered ESAs for 9-16 weeks. All but three studies were funded by the pharmaceutical industry. Overall, the analysis found that ESAs provided a small but clinically important improvement in anaemia-related symptoms. Of note, the median baseline haemoglobin was $10.1 \mathrm{~g} \mathrm{dl}^{-1}$ and during treatment, ESA-treated patients had a median haemoglobin level that was about $2 \mathrm{~g} \mathrm{dl}^{-1}$ greater than the placebo/control patients. For fatigue-related symptoms, the overall effect did not reach the threshold for a clinically important difference. The authors rightfully caution that harmful effects of ESAs should be balanced against potential benefits and that whether ESAs are safe for cancer patients undergoing chemotherapy continue to be viewed as a matter of debate (Bohlius et al, 2014).

Where are we now with this journey? While ESAs have been among the most widely prescribed agents in oncology, it has been a bumpy ride. What seemed so simple-a drug with support of basic science studies suggesting that its use might cure cancers, observational studies correlated serum haemoglobin levels with QOL and even overall survival, and clinical trials suggested that ESAs might also directly improve survival from cancer-is now far more complex. As an oncologist, a cancer survivor, and health services researcher, we have travelled different paths yet have arrived at a similar address as Brian Leyland-Jones-ESAs are powerful pharmacologic tools and should be treated with great respect. A related lesson that we have recently reported is that clinical initiatives that appear to be simple and highly beneficial-such as adding a clinical reminder for cancer screening to an electronic medical record-are likely to be far more complex. With the electronic reminder, formal empirical analysis identified a surprising and unexpected result-the reminders appeared to lower (not raise) colorectal cancer screening rates among high-risk patients (Bian et al, 2012). Future studies are needed to carefully assess the impact of what appears to be simple efforts-raise the serum haemoglobin level or remind a physician to perform a cancer screening test. These studies should not be funded by the pharmaceutical industry or others who have financial interest in the outcomes. For ESAs, these may be the only ways to ferret out ESA effects on EpoRs, quality of life, thrombosis, and ultimately survival, but these studies are unlikely to be completed in the near future.

\section{ACKNOWLEDGEMENTS}

The National Cancer Institute (1R01CA165609-01A1) and the South Carolina SmartState Program, and the Doris Levkoff Meddin Medication Safety Center.

\section{REFERENCES}

Begley GC, Ellis LM (2012) Raise standards for preclinical cancer research. Nature 483: 531-533.

Bennett CL, Lai SY, Henke M, Barnato SE, Armitage JO, Sartor O (2010) Association between pharmaceutical support and basic science research on erythropoiesis stimulating agents. Arch Int Med 170: 1490-1498.

Bennett CL, Silver SM, Djulbegovic B, Samaras AT, Blau A, Gleason KJ, Barnato SE, Elverman KM, Courtney M, McKoy JM, Edwards BJ, Tigue CC, Raisch DW, Yarnold PR, Dorr DA, Kuzel TM, Tallman MS, Trifilio SM, West DP, Lai SY, Henke M (2008) Venous thromboembolism and mortality associated with recombinant erythropoietin and darbepoetin administration for the treatment of cancer-associated anemia. JAMA 299(8): 914-924.

Bian J, Bennett CL, Fisher DA, Riberiro M, Lipscomb J (2012) Unintended consequences of health information technology: evidence from Veterans Affairs colorectal cancer oncology watch intervention. J Clin Oncol 30(32): 3947-3952.

Bohlis J, Wilson J, Seidenfeld J, Piper M, Schwarzer G, Sandercock J, Trelle S, Weingart O, Bayliss S, Brunskill S, Djulbegovic B, Bennett CL, Langensiepen S, Hyde C, Engert E (2006) Erythropoietin or darbepoetin for patients with cancer. Cochrane Database Syst Rev 19: 3.

Bohlius J, Tonia T, Nüesch E, Jüni P, Fey MF, Egger M, Bernhard J (2014) Effects of erythropoiesis-stimulating agents on fatigue- and anaemiarelated symptoms in cancer patients: systematic review and meta-analyses of published and unpublished data. Br J Cancer 111(1): 33-45.

Bohlius J, Wilson J, Seidenfeld J, Piper M, Schwarzer G, Sandercock J, Trelle S, Weingart O, Bayliss S, Djulbegovic B, Bennett CL, Langensiepen S, Hyde C, Engert A (2006) Recombinant human erythropoietins and cancer patients: updated meta-analysis of 57 studies including 9353 patients. J Natl Cancer Inst 98(10): 708-814. 
Glaser CM, Milesi W, Kornek GV, Lang S, Schüll B, Watzinger F, Selzer E, Lavey RS (2001) Impact of haemoglobin level and use of recombinant erythropoietin on efficacy of pre-operative chemoradiation therapy for squamous cell carcinoma of the oral cavity and oropharnyx. Int J Radiat Oncol Biol Phys 50: 705-715.

Henke M, Lassig R, Rube C, Schäfer U, Haase KD, Schilcher B, Mose S, Beer KT, Burger U, Dougherty C, Frommhold H (2003) Erythropoietin to treat head and neck cancer patients with anaemia undergoing radiotherapy- randomized, double-blind placebo-controlled trial. Lancet 362: $1255-1260$.

John L (2007) Chemo Disney: Ortho Biotech Markets Procrit Using Virtual Reality. Breast Cancer Action, 24 October 2007. http://archive.bcaction. org/index.php?page $=$ ortho-biotech.

Leyland-Jones B (2013) Erythropoiesis stimulating agents: a personal journey. J Natl Cancer Inst 105: 999-1001.
Leyland-Jones B. BEST Investigators and Study Group (2003) Breast cancer trial with erythropoietin terminated unexpectedly. Lancet Oncol 4: $459-460$.

Littlewood TJ, Bajetta E, Nortier JWR, Vercamen E, Rappaport B (2001) Effects of epoetin alfa on hematologic parameters and quality of life in cancer patients undergoing nonplatinum chemotherapy: results of a randomized double-blind placebo-controlled trial. J Clin Oncol 19: 2865-2874.

Silver DF, Piver MS (1999) Effects of recombinant human erythropoietin on the antitumor effect of cisplatin in SCID mice bearing human ovarian cancer: a possible oxygen effect. Gynecol Oncol 73(2): 280-284.

Vogelzang NJ, Breitbart W, Cella D, Curt GA, Groopman JE, Horning SJ, Itri LM, Johnson DH, Scherr SL, Portenoy RK (1997) Patient, caregiver, and oncologist perceptions of cancer-related fatigue: results of a tripart assessment survey. the fatigue coalition. Semin Hematol 34(3 Suppl 2): 4-12. 